\title{
Avaliação ergonômica da colheita florestal em área com madeira danificada pelo vento
}

\author{
Stanley Schettino ${ }^{*}$, Luciano José Minette², Denise Ransolin Soranso ${ }^{3}$, Anna Carolina Minetti \\ Camarinha $^{4}$, Carolina Freitas Schettino ${ }^{5}$
}

RESUMO: Este estudo teve por objetivo realizar a análise ergonômica do trabalho de seis atividades de colheita florestal em área danificada pelo vento. Para cada uma das atividades, foi realizada a avaliação biomecânica, através da aplicação do Modelo Biomecânico Tridimensional de Predição de Posturas e Forças Estáticas (3DSSPP ${ }^{\mathrm{TM}}$ ), desenvolvido pela Universidade de Michigan, além dos fatores ambientais calor, vibração e ruído, de forma a determinar os riscos ergonômicos a que os trabalhadores estavam expostos durante o desenvolvimento da colheita florestal. A avaliação biomecânica indicou que para as atividades de extração e carregamento manual os valores de carga estavam acima do limite recomendado, com elevado risco de desenvolvimento de lesões na coluna vertebral e nas articulações avaliadas. As condições térmicas do ambiente de trabalho, apresentaram risco aos trabalhadores, principalmente no período da tarde e em todas as atividades. O ruído foi o fator ambiental que apresentou maior risco ergonômico aos trabalhadores das atividades de derrubada e traçamento, seguido da vibração. Conclui-se que a colheita de madeira em área danificada pelo vento possui elevado risco ergonômico para os trabalhadores durante a execução de suas atividades, o que, aliado as condições ambientais adversas, proporciona elevados e iminentes riscos de desenvolvimento de lesões e doenças osteomusculares relacionadas ao trabalho.

Palavras-chave: Atividades florestais, riscos ergonômicos, saúde do trabalhador.

\section{Ergonomic evaluation of forest harvest in the area wood damaged by the wind}

\begin{abstract}
This study aimed to perform the ergonomic analysis of the work of six wood harvesting activities in a wind-damaged area. For each of the activities, the biomechanical evaluation, through the application of the Threedimensional Static Strength Prediction Program (3DSSPP ${ }^{\mathrm{TM}}$ ), developed by the University of Michigan, in addition to the environmental factors heat, vibration and noise were carried out in order to determine the ergonomic risks to which the workers were exposed during the development of the forest harvest. Biomechanical evaluation indicated that for manual extraction and loading activities the load values were above the recommended limit, with a high risk of developing spinal and joint injuries. The thermal conditions of the work environment presented a risk to workers, especially in the afternoon and in all activities. Noise was the environmental factor that presented a greater ergonomic risk to workers in the clearing and trapping activities, followed by vibration. It is concluded that the harvesting of wood in a damaged area by the wind poses a high ergonomic risk to the workers during the execution of their activities, which, together with adverse environmental conditions, provides high and imminent risks of developing work-related musculoskeletal disorders and diseases.
\end{abstract}

Keywords: Forest activities, ergonomic risks, worker's health.

\section{INTRODUÇÃO}

O setor brasileiro de florestas tornou-se, nos últimos anos, um dos mais relevantes no cenário global. Com uma área de 7,8 milhões de hectares de árvores plantadas, é responsável por $91 \%$ de toda a madeira produzida para fins industriais no País e um dos que apresenta maior potencial de contribuição para a construção de uma economia verde (IBÁ, 2016). Deste total, o Estado de Minas Gerais é detentor de $17 \%$ da área de florestas plantadas no Brasil, com grande predominância de plantios de eucaliptos, destinados principalmente para a indústria de celulose e produção de carvão vegetal.

Entretanto, em algumas regiões deste Estado, é comum a ocorrência de fortes ventos que causam danos e prejuízos a estes plantios, principalmente no Vale do Rio Doce. Ferreira et al. (2010), Rosado et

Recebido em 23/01/2018; Aceito para publicação em 21/03/2018

${ }^{1}$ Universidade Federal de Minas Gerais.

${ }^{2}$ Universidade Federal de Viçosa.

${ }^{3}$ Universidade Federal do Espírito Santo.

${ }^{4}$ Pontifícia Universidade Católica do Rio de Janeiro.

${ }^{5}$ Universidade Federal de Santa Catarina.

*E-mail: schettino@ufmg.br 
al. (2013) e Braz et al. (2014) relataram este problema em plantios de eucalipto nesta região, onde tempestades ocasionaram prejuízos provocados por rajadas de ventos, que geralmente ocorrem nos períodos de chuva entre os meses de outubro a março.

A ação dos ventos é um fator natural e impossível de ser controlada, podendo proporcionar estresse nas árvores, afetar a produtividade e a qualidade da madeira, além de causar danos irreversíveis, como inclinação do tronco em diferentes ângulos (BOSCHETTI et al., 2015). Ainda, de acordo com Ataíde et al. (2015), além de penalizar a qualidade da madeira e a produtividade da extração comercial, tais danos contribuem para dificultar as operações de colheita.

Os danos pelos ventos afetam negativamente toda a cadeia produtiva das florestas plantadas. Quando ocorre a quebra das árvores, a colheita deste material é mais onerosa e demanda maior tempo devido ao menor diâmetro de suas toras; nos casos em que há entortamento da árvore, o povoamento perderá parte da sua produtividade e como as árvores apresentam tortuosidade, a colheita também será mais demorada e onerosa; e, em ambos os casos, a mecanização da colheita se torna inviável (MITCHELL, 2012).

Diante de tal cenário, onde a força humana é imprescindível e os fatores ambientais nem sempre são favoráveis, os trabalhadores da colheita florestal acabam expostos a situações que apresentam elevados dispêndio energético, manuseio e levantamento de cargas, posturas inadequadas, repetitividade e índices de acidentes de trabalho, além da possibilidade do desenvolvimento de distúrbios osteomusculares (SILVA et al., 2008; FIEDLER et al., 2011, TORRES et al., 2014). Outro agravante são as características peculiares dessa modalidade de colheita, tais como: acessibilidade e mobilidade restritas, terrenos íngremes, exposição às condições climáticas extremas, ferramentas mal desenvolvidas e consequentemente inadequadas e mão de obra pouco qualificada. Estes e outros fatores contribuem para o desenvolvimento de doenças relacionadas ao trabalho e riscos a saúde e integridade física dos trabalhadores

Ainda, quando o trabalhador adota uma postura forçada por períodos prolongados, existe risco eminente de uma sobrecarga mecânica, que pode desencadear quadros álgicos e desequilíbrios de força, colocando em risco, desta forma, a integridade física e psíquica do trabalhador (SCHETTINO et al., 2017). Â medida que aumenta a fadiga, reduz-se o ritmo de trabalho, atenção e rapidez de raciocínio, tornando o trabalhador menos produtivo e mais sujeito a erros e acidentes (MOTA et al., 2016).

Dentre os principais fatores ergonômicos relacionados às atividades de colheita florestal, os biomecânicos (envolvendo as posturas, as forças aplicadas, a carga de trabalho físico e os movimentos repetitivos) e os ambientais (temperatura, ruído e vibração) têm influência direta sobre a saúde do trabalhador e consequentemente sobre a eficiência da operação, os quais podem ser minimizados por meio da adaptação ergonômica do trabalho e da forma de execução das atividades às características do ser humano (IIDA; BUARQUE, 2016).

Diante do exposto, através das avaliações biomecânica e do ambiente de trabalho, este estudo teve como objetivo determinar os riscos ergonômicos a que os trabalhadores estavam expostos durante o desenvolvimento das atividades de colheita de madeira danificada pelo vento.

\section{MATERIAL E MÉTODOS}

\section{Caracterização da amostragem}

Este estudo foi realizado em áreas de plantio de eucalipto pertencentes a uma propriedade rural localizada no Município de Virginópolis, Minas Gerais (18\%49'22" de latitude ao Sul da linha do Equador e 42\% $42^{\prime} 14 "$ de longitude a Oeste de Greenwich). A propriedade possuía 120 hectares ocupados por plantios comercias de eucalipto os quais, em sua grande maioria, haviam sido acometidos por fortes ventos aos cinco anos de idade e, consequentemente, apresentavam a madeira bastante danificada, tornando necessária sua imediata colheita (Figura 1). Os levantamentos de campo foram realizados nos meses de outubro e novembro de 2014, período em que estava sendo realizada a colheita.

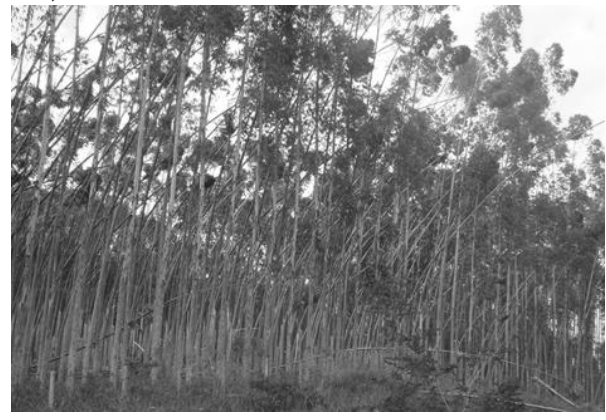


Figura 1. Florestas de eucalipto danificadas pelo vento na região do Vale do Rio Doce, Minas Gerais (Fonte: os autores).

A região apresenta uma altitude média de 800 metros. Segundo a classificação climática de Köppen, o clima predominante na região é Aw tropical chuvoso de savana, ou seja, inverno seco e chuvas máximas no verão, sendo que a estação chuvosa ocorre entre os meses de outubro e março. A precipitação pluviométrica média anual é de 1.300 mm. O solo da região foi classificado como Latossolo Vermelho-amarelo álico, textura argilosa e a topografia é ondulada (TONELLO et al., 2006).

A amostra abrangeu nove trabalhadores, correspondendo a $100 \%$ da população, com idade

média de 41,0 anos, peso médio de $68,0 \mathrm{Kg}$ e estatura média de 1,69 m. Todos os trabalhadores foram informados sobre os objetivos e a metodologia do trabalho, tendo assinado o Termo de Consentimento Livre e Esclarecido estando, portanto, em conformidade com a Resolução $\mathrm{n}^{\circ}$ 196/1996 da Comissão de Ética em Pesquisa do Ministério da Saúde.

As atividades florestais analisadas encontram-se caracterizadas na Tabela 1 .

Tabela 1. Descrição das atividades de colheita florestal analisadas.

\begin{tabular}{ll}
\hline \multicolumn{1}{c}{ Atividades } & \multicolumn{1}{c}{ Caracterização da atividade } \\
\hline Roçada pré corte & Remoção do sub-bosque, realizada manualmente com o auxílio de uma foice, pesando 750 g. \\
\hline Derrubada & $\begin{array}{l}\text { Abate das árvores. Em cada árvore, o trabalhador realiza a abertura da boca de corte na face do tronco } \\
\text { direcionada para o sentido desejado de queda, realizando, em seguida, o corte final na face oposta da árvore. } \\
\text { Realizada com motosserra cuja massa é, em média, igual a 7,0 kg. }\end{array}$ \\
\hline Desgalhamento & $\begin{array}{l}\text { Retirada dos galhos das árvores, desde a base até o topo e, chegando neste ponto, efetua também o } \\
\text { destopamento da árvore. Realizada de forma manual, utilizando machadinha com massa de } 0,65 \mathrm{~kg} .\end{array}$ \\
\hline \multirow{2}{*}{ Traçamento } & $\begin{array}{l}\text { Seccionamento dos troncos das árvores em toretes com tamanho pré-determinado, em geral com 2,50 m. } \\
\text { Realizada com motosserra cuja massa é, em média, igual a 7,0 kg. Pode ser realizado no interior dos talhões } \\
\text { ou na margem das estradas. }\end{array}$ \\
\hline \multirow{2}{*}{ Extração manual } & $\begin{array}{l}\text { Consiste em dar "tombos" nos toretes no sentido da declividade do terreno, empurrando-os com as mãos ou } \\
\text { pés e arrastando com a machadinha; essa, com massa de 0,65 kg. Quando os toretes chegam à margem da } \\
\text { estrada, os trabalhadores realizam o empilhamento manual dos mesmos, deixando a madeira pronta para o } \\
\text { carregamento. }\end{array}$ \\
\hline Carregamento \\
manual
\end{tabular}

\section{Avaliação biomecânica}

A avaliação biomecânica, através da metodologia proposta pela Universidade de Michigan, foi realizada por análise tridimensional, através de fotos e filmagens dos trabalhadores na execução da atividade em diversas posturas. Para cada fase da atividade e a partir do congelamento dos movimentos, os ângulos formados nas articulações (punho, cotovelo, ombro, tronco, coxofemorais, joelho e tornozelo) foram medidos, além da força de compressão no disco entre as vértebras Lombar 5 e Sacral $1\left(\mathrm{~L}_{5}-\mathrm{S}_{1}\right)$ da coluna vertebral. Os ângulos, associados às características das forças utilizadas, como magnitude e direção, à quantidade de mãos utilizadas e às características antropométricas de altura e peso da população em estudo, foram empregados para a realização da análise, tendo sido selecionadas as posturas estáticas forçadas e medidos os ângulos para inserção no programa computacional de Modelo Biomecânico Tridimensional de Predição de Posturas e Forças Estáticas (3DSSPP ${ }^{\mathrm{TM}}$ ), versão 5.0.9, desenvolvido pela Universidade de Michigan, dos Estados Unidos (UNIVERSITY OF MICHIGAN, 2013). Dentro de cada fase dos ciclos da atividade, foram selecionadas as posturas representativas para serem analisadas biomecanicamente.

O programa computacional forneceu a carga limite recomendada, que corresponde ao peso que mais de $99 \%$ dos homens e $75 \%$ das mulheres em boas condições de saúde conseguem levantar. Essa carga limite induz a uma força de compressão (Newton) da ordem de $3.426,3 \mathrm{~N}$ sobre o disco $\mathrm{L}_{5}-\mathrm{S}_{1}$ da coluna vertebral, que pode ser tolerada pela maioria dos trabalhadores jovens e em boas condições de saúde. Ainda, para cada articulação avaliada foi fornecido pelo programa o percentual de trabalhadores capazes de exercer a atividade sem o desenvolvimento de lesões osteomusculares, representando o potencial lesivo ao trabalhador em cada fase da atividade.

Nas atividades onde havia manuseio de cargas, para a determinação dos esforços musculares e da análise biomecânica, os dados foram levantados por meio de medições diretas das forças envolvidas nas atividades com o uso de uma célula de carga da marca Kratos, modelo IDDK, com capacidade para até $1.000 \mathrm{~N}$.

\section{Avaliação de Fatores Ambientais}


A avaliação da exposição ao ruído ocupacional foi realizada utilizando um medidor do nível equivalente de ruído (dosímetro), marca $01 \mathrm{~dB}$ Metravib, modelo Wed007, nível de compensação A e em circuito de resposta lenta. O microfone foi instalado próximo ao ouvido dos trabalhadores, utilizando-se a metodologia da Norma de Higiene Ocupacional (NHO) $\mathrm{N}^{\circ} 01$ da Fundação Jorge Duprat Figueiredo, de Segurança e Medicina do Trabalho - FUNDACENTRO, vinculada ao Ministério do Trabalho e Emprego - MTe (FUNDACENTRO, 2001a). Os valores obtidos foram confrontados com os limites máximos de exposição determinados pela Norma Regulamentadora (NR) $\mathrm{N}^{\circ} 15$ - Atividades e Operações Insalubres, do MTe, em seu Anexo 1 (BRASIL, 1978).

O ambiente térmico do local de trabalho foi avaliado por meio do uso do medidor de Índice de Bulbo Úmido e Termômetro de Globo - IBUTG modelo TGD 400. Os aparelhos foram posicionados no ambiente de trabalho, junto às atividades, e as leituras realizadas a cada 5 minutos durante, no mínimo, 120 minutos, conforme metodologia da NHO-06 (FUNDACENTRO, 2001b). Os valores obtidos foram confrontados com os limites máximos de exposição determinados pela NR-15, Anexo 3 (BRASIL, 1978). De modo a correlacionar o conforto térmico ao ambiente de trabalho, o IBUTG funciona como um indicador, englobando os principais fatores causadores da sobrecarga térmica (alta temperatura, metabolismo, calor radiante e alta umidade relativa do ar), além dos principais agentes atenuadores da mesma (ventilação do ambiente, baixa umidade relativa do ar e baixa temperatura), estabelecendo o tempo de trabalho e repouso (COUTO, 2002).

$\mathrm{Na}$ avaliação da vibração foi utilizado um medidor marca $01 \mathrm{~dB}$, modelo Maestro, o qual possui um acelerômetro triaxial (direções X, Y e Z) e um aparelho registrador dos valores de aceleração em $\mathrm{m}$ $\mathrm{s}^{-2}$. O acelerômetro foi instalado nas mãos e dedos dos operadores. A avaliação foi realizada de acordo com a metodologia estabelecida nas Normas ISO 2631 e ISO/DIS 5349. Os resultados das medições foram comparados com os valores recomendados pela NHO-10 (FUNDACENTRO, 2013), expressos em aceleração resultante de exposição normalizada (Aren), bem como com os limites máximos de exposição determinados no Anexo 8 da NR-15 (BRASIL, 1978).

\section{RESULTADOS}

\section{Avaliação Biomecânica}

Os resultados das análises das forças aplicadas nas articulações e no disco $\mathrm{L}_{5}-\mathrm{S}_{1}$ da coluna vertebral dos trabalhadores avaliados, bem como dos percentuais de capazes (indivíduos aptos) para cada uma das articulações estudadas, são apresentados na Tabela 2.

Verifica-se que as atividades de extração e carregamento manual apresentaram forças de compressão no disco $\mathrm{L}_{5}-\mathrm{S}_{1}$ da coluna vertebral igual a 5.910 e $5.180 \mathrm{~N}$, respectivamente. Tais valores são substancialmente superiores ao limite máximo recomendado pelo modelo $3 \mathrm{DSSPP}^{\mathrm{TM}}$, que é de $3.426 \mathrm{~N}$, indicando iminente de risco de lesão nas articulações da coluna vertebral para os trabalhadores que desenvolvem essas atividades. Para as demais atividades, os valores de compressão neste disco da coluna vertebral foram menores que o valor limite, indicando a ausência de risco de lesão à coluna vertebral.

Ao se analisar os riscos de lesões nas articulações para as diferentes atividades avaliadas, verificou-se que a extração e o carregamento manual se destacaram negativamente por apresentar altíssimo risco de lesões para os membros superiores, sendo que apenas $4 \%$ dos trabalhadores são capazes de exercer essa função sem risco de lesões para as articulações do punho e $1 \%$ para as articulações do tronco. Ainda, merece destaque o fato de que $100 \%$ dos trabalhadores envolvidos nessas atividades apresentam risco de lesão às articulações dos ombros. Por fim, ambas as atividades apresentaram elevado risco de lesão as articulações dos cotovelos, estando o percentual de capazes na ordem de 33 e $64 \%$ para as atividades de extração e carregamento manual, respectivamente.

Em uma floresta atingida por ventos, cujos troncos apresentam elevada inclinação e quebra de árvores, a colheita torna-se mais onerosa e difícil sob a ótica técnico-operacional. Vale ressaltar que, em condições normais, tal colheita seria mecanizada ou semimecanizada, o que resultaria em menores custos, maiores produtividades e menores riscos de desenvolvimento de lesões e doenças osteomusculares relacionadas ao trabalho (RODRIGUES; BELLINI, 2010).

A colheita florestal em áreas declivosas, quando realizada de forma manual, já apresenta elevados índices de acidentes e riscos de desenvolvimento de doenças ocupacionais (BARBOSA et al., 2014; COELHO et al., 2017). Entretanto, em um cenário de florestas atingidas por ventos quando ocorre a quebra das árvores, a colheita se torna mais difícil (BRAZ, et al., 2014), havendo um predomínio das atividades realizadas de forma manual e, conforme a maneira como as operações e suas atividades são executadas, muitas vezes os trabalhadores levantam e transportam carga com pesos acima dos limites 
toleráveis e realizam movimentos em posturas incorretas e repetitivas durante vários anos. Essa manutenção excessiva ou repetitiva de posturas, movimentos e manuseio de cargas são fatores de risco que ameaçam a integridade do sistema osteoarticular vertebral, podendo levar a um desgaste de todas as articulações envolvidas, comprometendo seriamente as condições de saúde dos trabalhadores (SILVA et al., 2008), ou seja, potencializando os já presentes fatores de risco para a ocorrência de acidentes e, ou, desenvolvimento de doenças ocupacionais.

No contexto deste estudo, apenas as atividades de extração e carregamento manual apresentaram valores de força de compressão no disco $\mathrm{L}_{5}-\mathrm{S}_{1}$ da coluna vertebral acima do limite máximo recomendado pelo modelo $3 \mathrm{DSSPP}^{\mathrm{TM}}$, que é de 3.426,3 N. Ambas as atividades apresentam particularidades, tais como posturas com os braços esticados e o tronco inclinado concomitantemente, fatores que, de acordo com Xu e Cheng (2014), culminam no deslocamento do centro de gravidade para fora do corpo e na geração de forças de compressão excessivas sobre o disco $\mathrm{L}_{5}-\mathrm{S}_{1}$.

Outros fatores contributivos para tais resultados são as posturas assimétricas e o levantamento e transporte de cargas, comum a ambas as atividades. Tais situações, de acordo com Silva et al. (2008), podem provocar degeneração dos discos articulares, sendo a coluna lombar a que mais sofre em função da sustentação do tronco, apresentando assim maior incidência de dores. Ainda, segundo Couto (2002), os distúrbios dos discos vertebrais são decorrentes de forças de compressão elevadas, podendo esses distúrbios ocasionar dor muito forte e extremamente incapacitante, acabando por gerar afastamentos prolongados e, até mesmo, permanentes, já que os trabalhadores têm redução de sua capacidade para realizar atividades pesadas.

Ao analisar os resultados dos riscos de lesões as demais articulações avaliadas, ficou evidenciado que, em geral, os membros inferiores são os mais afetados quando do desenvolvimento das atividades de colheita de madeira em áreas danificadas por ventos. De acordo com Minette et al. (2015), podem ser considerados agravantes a declividade do terreno, prejudicando a postura dos trabalhadores e obrigando-os a repetidas vezes apoiarem todo o peso do corpo e dos equipamentos em uma única perna; e as longas distâncias percorridas pelos trabalhadores em terrenos íngremes e com obstáculos como pedras, buracos e resíduos de colheita. Ainda, o elevado percentual de tempo em que os trabalhadores permaneceram nas posturas típicas, para todas atividades avaliadas, fornece um indicativo de que a postura é um fator crítico e que necessita de ações corretivas de forma a evitar futuros problemas de saúde aos trabalhadores.

Ainda, sob a ótica da biomecânica ocupacional, merece destaque negativo as atividades de extração e carregamento manual, as quais apresentaram alarmantes riscos de desenvolvimento de lesões nas articulações dos punhos, cotovelos, ombros e tronco. Os resultados das avaliações sugerem que $100 \%$ dos trabalhadores envolvidos na atividade de carregamento manual possuem risco de desenvolvimento de lesões nos ombros. A sobrecarga postural nos trabalhadores se caracteriza quando este se encontra fora da posição corporal neutra por um determinado período de tempo, favorecendo o surgimento de fadiga muscular, dores, inflamações e até lesões nos músculos e ligamentos dos membros inferiores (TORRES et al., 2014), chegando até mesmo a ocasionar a invalidez permanente para o trabalho.

De acordo com Schettino et al. (2016), um dos causadores de tais distúrbios pode estar associado ao caráter repetitivo das tarefas, porém não é o único elemento a que se atribui essas disfunções musculoesqueléticas. Segundo os autores, essas disfunções podem ter relações com a postura e com a força exigidas pelas tarefas e fatores ambientais, como a temperatura ambiente e os terrenos irregulares. Além disso, os aspectos mentais e psicológicos e relacionados a organização do trabalho podem também se associar a tais lesões (BOSCHMAN et al., 2012).

\section{Avaliação de Fatores Ambientais}

Durante o período de avaliação, foi encontrado um índice de bulbo úmido e termômetro de globo (IBUTG) médio de $28,1^{\circ} \mathrm{C}$, variando de $22,9^{\circ} \mathrm{C}$ a $31,7^{\circ} \mathrm{C}$. Este valor deixa evidente a sobrecarga térmica e extrapola os limites legais, não sendo permitido o trabalho sem a adoção de medidas adequadas de controle.

O valor obtido para o nível de ruído equivalente (Leq) nas atividades de derrubada e traçamento foi de $89,3 \mathrm{~dB}(\mathrm{~A})$, valor que se encontra acima dos limites legais para uma jornada diária de trabalho de 8 horas. Para as demais atividades, os níveis de Leq ficaram abaixo dos limites legais, não representando risco ocupacional aos trabalhadores.

$\mathrm{Na}$ avaliação da vibração, o valor de aceleração resultante de exposição normalizada para vibração de mãos e braços encontrado, para as atividades de derrubada e traçamento, foi igual a $4,86 \mathrm{~m} \cdot \mathrm{s}^{-2}$ estando, portanto, abaixo do limite de exposição diária e não representando riscos à saúde $\mathrm{e}$ segurança dos trabalhadores. Contudo, é importante salientar que o valor encontrado foi superior ao nível de ação que é de $2,5 \mathrm{~m} \cdot \mathrm{s}^{-2}$, requerendo atenção e 
medidas preventivas para evitar danos futuros a saúde dos trabalhadores.

Tabela 2. Resultados da avaliação biomecânica para as atividades de colheita florestal em área danificada por ventos.

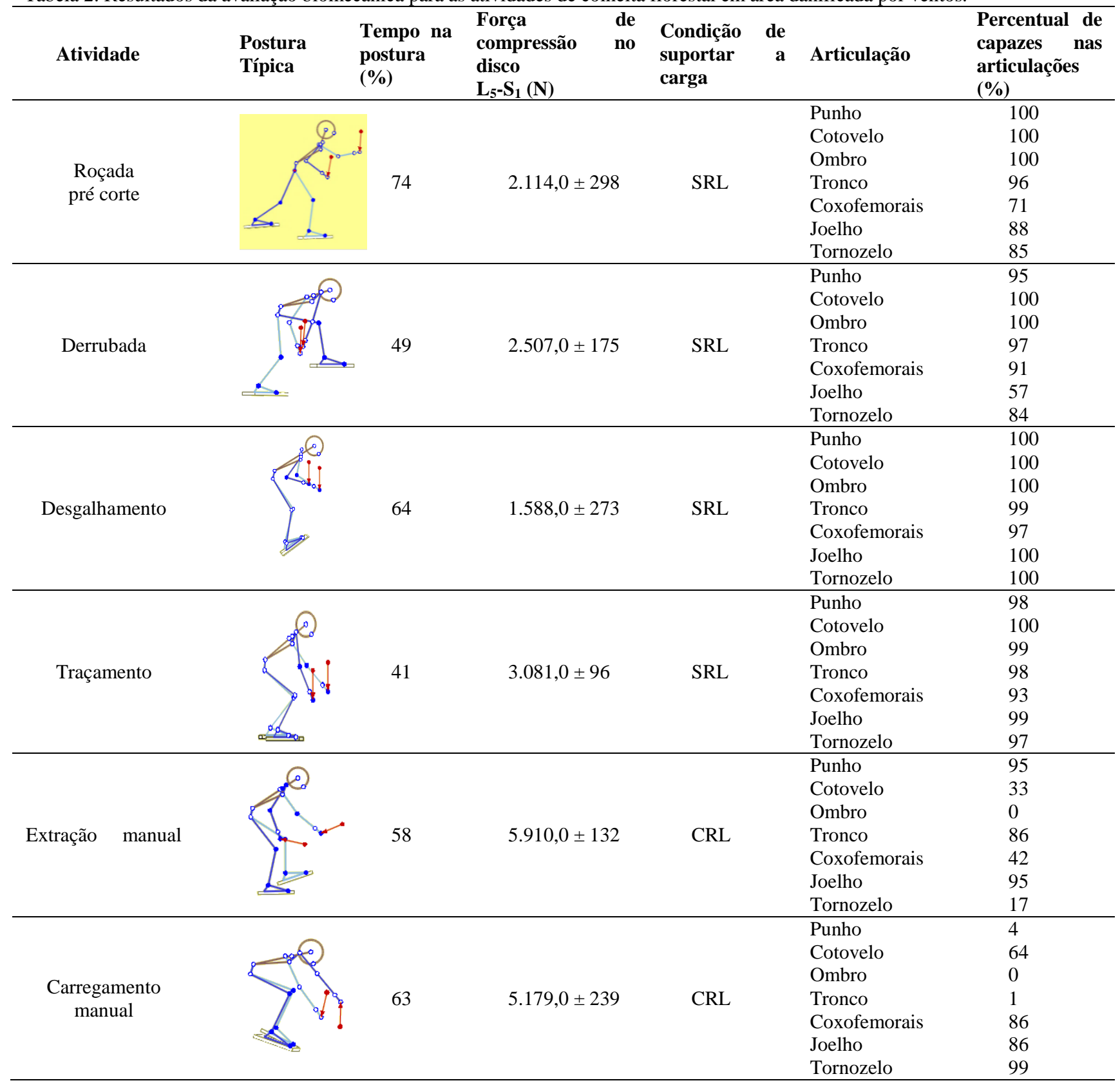

Obs.: SRL = postura sem risco de lesão nas articulações da coluna vertebral; CLR = postura com risco de lesão nas articulações da coluna vertebral.

Sob as condições em que a colheita de madeira em áreas atingidas por ventos é realizada (geralmente de forma manual ou semimecanizada), o ser humano pode estar sujeito a diversas situações que podem causar problemas de saúde, fadiga e desconforto, levando a um aumento dos índices de acidentes, diminuição da concentração, da qualidade e da produtividade do trabalho. Tais circunstâncias são muito comuns no setor florestal, onde a maioria dos trabalhadores executa o trabalho em campo aberto exposto a intempéries como insolação excessiva, calor, vento, frio, chuva (BATISTA et al., 2014).
O conforto térmico reflete a sensação de bemestar do ser humano com o ambiente, sendo resultado de uma combinação a temperatura do ambiente, a umidade relativa do ar e a velocidade relativa do ar (FROTA; SCHIFFER, 2016). Sob condições inadequadas em relação a sobrecarga térmica, torna-se necessário reduzir o tempo de permanência do trabalhador no local de trabalho, devendo ser feito o rodízio de funções e o estabelecimento de pausas laborais para descanso e reidratação (COUTO, 2002).

Em outra vertente, Fiedler et al. (2007) afirmam que valores acima de IBUTG de $30^{\circ} \mathrm{C}$ potencializam 
riscos de lesões à saúde do trabalhador, a precisão do trabalho e a produtividade diminuem e verifica-se uma tendência de aumento dos acidentes. Corroborando tal afirmativa, Lundgren et al. (2014) ao analisarem o estresse causado pelo calor associado com a redução de produtividade, concluíram que valores altos de IBUTG tiveram significante impacto na produtividade, em todos os locais de trabalho avaliados.

Ao estabelecer os limites de tolerância para a exposição aos níveis de ruído, a legislação busca oferecer um ambiente de trabalho dentro de limites aceitáveis, visto que a sensação de desconforto causada por esse agente afeta física $\mathrm{e}$ psicologicamente o ser humano, causando, dependendo dos níveis, desde irritações até lesões irreversíveis no aparelho auditivo do trabalhador, principalmente a surdez definitiva (BATISTA et al., 2014).

A exposição a níveis de ruído elevados no ambiente de trabalho pode implicar em perda auditiva do trabalhador (KROEMER; GRANDJEAN, 2005), causar alterações cardiovasculares, psicológicas e respiratórias, distúrbios do sono, disfunções no sistema imunológico, irritabilidade e fadiga, além de diminuir o desempenho do trabalhador nas suas funções, aumentando a probabilidade de ocorrência de acidentes no trabalho (MASSA et al., 2012; DUARTE et al., 2105). Os resultados das avaliações realizadas neste estudo indicam que os trabalhadores que desempenham as atividades de colheita de madeira em áreas atingidas por ventos encontram-se vulneráveis frente ao agente de risco ruído.

$\mathrm{Na}$ avaliação da exposição a vibração ocupacional, os valores encontrados para as atividades de derrubada e traçamento deixam clara a necessidade de reorganização do trabalho. Considerando que a vibração é um importante agente de risco ocupacional, é desejável que sejam observados uma série de critérios no que tange às normas de uso das motosserras, pois respeitar os limites de uso diário e estabelecer períodos de pausa, bem como as condições de adequação para uso do equipamento (tempo de vida útil, frequência de manutenção), são medidas imprescindíveis para minimizar o aparecimento de lesões geradas em função da exposição à vibração (SCHETTINO et al., 2016).

Ainda, segundo Langer et al. (2015), as vibrações podem originar perturbações neurológicas ou musculares, vasculares e lesões osteoarticulares, no caso das vibrações transmitidas ao sistema mãos e braços, e patologias na região lombar e lesões da coluna vertebral para o caso das vibrações transmitidas a todo o organismo.

\section{CONCLUSÕES}

Nas condições em que este estudo foi realizado, os resultados permitiram concluir que:

- A colheita de madeira em área danificada pelo vento possui elevado risco ergonômico para os trabalhadores durante o desenvolvimento das atividades, favorecendo o surgimento de lesões e doenças relacionadas ao trabalho.

- A avaliação biomecânica indicou a existência de iminente e significativo risco de lesão nas articulações da coluna vertebral para as atividades de extração e carregamento manual. Em todas as atividades existe o risco de desenvolvimento de lesões nas demais articulações avaliadas, principalmente nos membros superiores para a extração e o carregamento manual e nos membros inferiores para as demais atividades.

As condições térmicas do ambiente de trabalho não estavam em conformidade com os limites de tolerância estabelecidos para a exposição ao calor, sendo necessário a adoção de medidas organizacionais e de controle da exposição dos trabalhadores a este agente.

$\mathrm{O}$ ruído apresentou-se como risco para as atividades envolvendo a utilização de motosserra. Já os níveis de vibração emitidos pela motosserra estavam em conformidade com o limite normativo estabelecido, embora sejam necessárias ações para sua redução.

\section{REFERÊNCIAS}

ATAíde, G. M.; CASTRO, R. V. O.; CORREIA, A. C. G.; REIS, G. G.; REIS, M. G. F.; ROSADO, A. M. Interação árvores e ventos: aspectos ecofisiológicos e silviculturais. Ciência Florestal, Santa Maria, v. 25, n. 2, p. 523-536, 2015.

BARBOSA, R.P.; FIEDLER, N.C.; CARMO, F.C.A.; MINETTE, L.J.; SILVA, E.N. Análise de posturas na colheita florestal semimecanizada em áreas declivosas. Revista Árvore, Viçosa, v. 38, n. 4, p. 733-738, 2014.

BATISTA, J. V.; SAMPAIO, O. B.; SILVA, F. F. A influência de fatores climáticos e ambientais sobre a saúde de trabalhadores florestais. Revista em Agronegócios e Meio Ambiente, Maringá, v. 7, n. 2, p. 359-390, 2014. 
BOSCHMAN, J. S.; MOLEN, H. F. V. M.; SLUITER, J. K.; DRESEN M. H. W. F. Musculoskeletal disorders among construction workers: a one-year follow-up study. BioMed Central Musculoskeletal Disorders, v. 13, p. 196, 2012.

BOSCHETTI, W. T.; PAES, J.B.; VIDAURRE, G.B.; ARANTES, M.D.C.; LEITE, F.P. Parâmetros dendrométricos e excentricidade da medula em árvores inclinadas de eucalipto. Scientia Forestalis. Piracicaba, v. 43, n. 108, p. 781-789, dez. 2015.

BRASIL. Ministério do Trabalho e Emprego. Portaria no 3.214, de 08 de junho de 1978. Aprova as Normas Regulamentadoras (NR) do Capítulo V, Título II, da Consolidação das Leis do Trabalho, relativas a Segurança e Medicina do Trabalho. Brasília: MTE, 1978.

BRAZ, R. L.; OLIVEIRA, J. T. O.; ROSADO, A. M.; VIDAURRE, G. B. V.; PAES, J. B. Parâmetros dendrométricos e resistência mecânica das árvores de clones de Eucalyptus em áreas sujeitas à ação dos ventos. Ciência Florestal, Santa Maria, v. 24, n. 4, p. 947-958, 2014.

COELHO, M.P.; LIMA, D.S.S.; FONSECA, G.C. Condições de saúde e trabalho na extração florestal manual em terrenos montanhosos. Ação Ergonômica, v. 12, n. 1, p. 64-72, 2017.

COUTO, H. A. Ergonomia aplicada ao trabalho em 18 lições. Belo Horizonte, Ergo Editora, 2002. 201 p.

DUARTE, A. S. M.; NG, R. T. Y.; CARVALHO, G. M.; GUIMARÃES, A. C.; PINHEIRO, L. A. M.; COSTA, E. A.; et al. Níveis elevados de pressão sonora: limiares dos reflexos estapedianos e queixas auditivas de trabalhadores expostos. Braz J Otorhinolaryngol. v. 81, p.374-383, 2015 .

FERREIRA, S.; LIMA, J. T.; TRUGUILHO, P. F.; SILVA, J. R. M. S.; ROSADO, A. M.; MONTEIRO, T. C. Resistência mecânica de caules de clones de Eucalyptus cultivados em diferentes topografias. Cerne, Lavras, v. 16, Supl., p. 133-140, 2010.

FIEDLER, N. C.; SANTOS, A. D. L.; GATTO, A. C.; LOPES, E. S.; OLIVEIRA, J. D. S. Avaliação das condições do ambiente de trabalho em atividades de poda de árvores. Cerne, Lavras, v. 13, n. 1, p. 19-24, 2007.

FIEDLER, N. C.; BARBOSA, R. P.; ANDREON, B. C.; GONÇALVES, S. B.; SILVA, E. N. Avaliação das posturas adotadas em operações florestais em áreas declivosas. Floresta e Ambiente, Seropédica, v. 18, n. 4, p. 402-409. 2011.

FROTA, A. B.; SCHIFFER, S. R. Manual de Conforto Térmico. ( $8^{\mathrm{a}}$ ed). São Paulo: Studio Nobel. 2016. 248 p. FUNDACENTRO - Fundação Jorge Duprat Figueiredo, de Segurança e Medicina do Trabalho. Norma de higiene ocupacional: NHO 01: Avaliação da exposição ocupacional ao ruído. São Paulo: Fundacentro, 2001a. $40 \mathrm{p}$.

FUNDACENTRO - Fundação Jorge Duprat Figueiredo, de Segurança e Medicina do Trabalho. Norma de higiene ocupacional: NHO 06: Avaliação da exposição ocupacional ao calor. São Paulo: Fundacentro, 2001b. 46 p.

FUNDACENTRO - Fundação Jorge Duprat Figueiredo, de Segurança e Medicina do Trabalho. Norma de higiene ocupacional: NHO 10: Avaliação da exposição ocupacional a vibração em mãos e braços. São Paulo: Fundacentro, 2013. 53 p.

IBÁ - Industria Brasileira de Árvores. Relatório IBÁ 2016. São Paulo: Pöyry Consultoria em Gestão e Negócios Ltda, 2016. 100 p.

IIDA, I.; BUARQUE, L. Ergonomia: projeto e produção. 3.ed. São Paulo: Edgard Blucher, 2016. 850 p.

KROEMER, K. H. E; GRANDJEAN, E. Manual de ergonomia: Adaptando o trabalho ao homem. 5.ed. Porto Alegre: Bookman, 2005, 327 p.

LANGER, T.H.; EBBESEN, M.K.; KORDESTANI, A. Experimental analysis of occupational whole-body vibration exposure of agricultural tractor with large square baler. International Journal of Industrial Ergonomics, v. 47, p. 79-83, 2015.

LUNDGREN, K.; KUKLANE, K.; VENUGOPAL, V. Occupational heat stress and associated productivity loss estimation using the PHS model (ISO 7933): a case study from workplaces in Chennai, India. Global Health Action, v. 7, n. 1, p. 25362, 2014.

MASSA, C. G. P.; RABELO, C. M.; MOREIRA, R. R.; MATAS, C. G.; SCHOCHAT, E.; SAMELLI, A. G. P300 in workers exposed to occupational noise. Brazilian Journal of Otorhinolaryngology, São Paulo, v. 78, n. 6, p. $107-112,2012$.

MINETTE, L. J.; SCHETTINO, S.; SOUZA, V. G. L.; DUARTE, C.L.; SOUZA, A.P. Avaliação biomecânica e da carga física de trabalho dos trabalhadores florestais em regiões montanhosas. Scientia Forestalis. Piracicaba, v.43, n.107, p. 541-550, 2015.

MITCHELL, S. J. Wind as a natural disturbance agent in forests: a synthesis. Forestry, v. 86, n. 2, p. 147-157, 2012.

MOTA, D.D.C.F.; CRUZ, D.A.L.M.; PIMENTA, C.A.M. Fadiga: uma análise do conceito. Acta Paulista de Enfermagem, v. 18, n. 3, p. 285-293, 2005.

RODRIGUES, P. F. V.; BELLINI, M. I. B. A organização do trabalho e suas repercussões na saúde do trabalhador e de sua família. Textos e Contextos. Porto Alegre, v. 9, n. 2, p. 345-357, 2010. 
ROSADO, A. M.; ATAÍDE, G. M.; CASTRO, R. V. O.; CORREIA, A. C. G. Avaliação da tolerância à quebra por vento em árvores de eucalipto via teste de resistência. Pesquisa Florestal Brasileira, Colombo, v. 33, n. 75, p. 309-315, 2013.

SCHETTINO, S.; CAMPOS, J.C.C.; MINETTE, L.J.; SOUZA, A.P. Work precariousness: ergonomic risks to operators of machines adapted for forest harvesting. Revista Árvore, v. 41, n. 1, p. 1-9, 2017.

SCHETTINO, S.; MiNETTE, L. J.; SOUZA, A. L.; SOUZA, A. P. Avaliação ergonômica do processo de mensuração florestal. Scientia Forestalis. Piracicaba, v.44, n.111, p. 575-586, 2016.

SILVA, E. P.; SOUZA, A. P.; MINETTE, L. J.; BAETA, F. C.; VIEIRA, H. A. N. F. Avaliação biomecânica do trabalho de extração manual de madeira em áreas acidentadas. Scientia Forestalis. Piracicaba, v.36, n.79, p. 231-235, 2008.

TONELLO, K. C.; DIAS, H. C. T.; SOUZA, A. L.; RIBEIRO, C. A. A. S.; LEITE, F. P. Morfometria da bacia hidrográfica da Cachoeira das Pombas, GuanhãesMG. Árvore, Viçosa, v. 30, n. 5, p. 849-857, 2006.
TORRES, B. P. L.; MUÑOZ, E. L. G.; RODRIGUEZ, C. C.; LÓPEZ, E. O. Evaluación de sobrecarga postural en trabajadores: revisión de la literatura. Ciencia \& Trabajo, Santiago, v. 16, n. 50, p. 111-115, 2014.

UNIVERSITY OF MICHIGAN. 3D Static Strenght Predition Program $^{\text {TM }}$. Version 5.0.9 - Users's manual. Michigan: University of Michigan. 2013.

XU, Y.W.; CHENG, A.S. An onsite ergonomics assessment for risk of work-related musculoskeletal disorders among cooks in a Chinese restaurant. Work, v. 48, n. 4, p. 539-545, 2014. 